The next volume deals with reproduction and development, and is the most tightly organized of them all. The reviews are arranged in a logical sequence and are relatively even in quality; the standard of illustration is particularly good. In his preface, Dukelow underlines the importance of studies of reproduction for conservation. The special value of the comparative approach is demonstrated most particularly in the contributions by Robinson and Goy on steroid hormones and the ovarian cycle, by Enders and Schlafke on implantation, by King on the morphology of the placenta and fetal membranes, by Brizee and Dunlap on growth (including a useful survey of gestation periods), and by Watts on skeletal development. The latter, incidentally, reveals an important gap in our knowledge: virtually nothing is known about skeletal development in prosimians.

Volume 4 is devoted to the neurosciences, and it too contains a number of good, well-illustrated surveys. It is perhaps unfortunate that, in the preface, Steklis refers to prosimian, monkey, ape and human as constituting a "quasi-evolutionary series", thus perpetuating the misleading notion of the Scala naturae as a suitable model for comparative study of primates. The contribution by Stephan et al. provides a survey of allometric analyses of the size of brain and parts, from one of the leading research groups involved with this topic. The review by Allman and McGuinness of the visual cortex is simply superb. Other highlights are the competent reviews by Rodieck of the primate retina (which unfortunately has little to say about prosimians), and by Eberhart of neural and hormonal correlates of sexual behaviour

Despite the unavoidable drawbacks of such a vast undertaking, the overall result is worthwhile. The editors have succeeded in producing a work that should be widely consulted, and the generous triple indexes (taxonomic, author and subject) will greatly facilitate its use. The only previous endeavour of this kind was the multivolume Primatologia (edited by Hofer, Schultz and Starck). Although that work is now well out of date, some of the reviews stand as classics that are still worth consulting. The same will surely be true of some of the contributions in Comparative Primate Biology in the years to come

R.D. Martin is Director of the Anthropological Institute and Museum, University of Zürich, CH-8057 Zürich, Switzerland.

- Also new for primatologists from Alan R. Liss is Ecology and Behavior of Food-Enhanced Primate Groups, edited by J. E. Fa and C. H. Southwick. The book is Vol 11 in the Liss series Monographs in Primatology, and presents studies of primates whose food is provided for them, contrasting these with the behavioural patterns of wild primate groups. Price is $\$ 59$. $£ 52.50$.

\section{Complex defences}

\section{Fred S. Rosen}

The Complement System. Edited by $\mathrm{K}$. Rother and G.O. Till. Springer-Verlag: 1988. Pp.535. DM180, £62, \$98.

THE long dispute between Ehrlich and Bordet, over whether complement is a single substance or a multiplicity of substances, makes for charmingly ingenuous reading today. At a time - the first decade of this century - when the world was still ravaged by tuberculosis, diphtheria and a host of now almost-forgotten infectious diseases, the public's imagination was captivated by the idea that something in the blood could indiscriminately kill germs. Complement, for example, in its English guise as the opsonins of Sir Almroth Wright, gave us that Shavian masterpiece, The Doctor's Dilemma.

In the end it turned out to be very complicated. The 20 proteins that constitute complement, and the complex interactions between them and their cell-membrane receptors, now stretch the credulity of medical students and leave most scientists in a state of stunned insouciance. Like the study of the clotting system, the complement system has been relegated to a kind of scholastic pursuit of a few crazed devotees. That is a pity because it has unique and exciting aspects for geneti- cists, biochemists, cell biologists, immunologists and microbiologists, and in clinical medicine.

Rother and Till have brought together a roster of experts from both sides of the Atlantic, and Japan, to give an account of our considerable knowledge of this subject. The results are very good and would certainly astound, if not embarrass, both Ehrlich and Bordet. During the assembly of the material, however, the genes encoding almost all of the complement components and their known receptors were cloned. This structural information will, one hopes, be included in the next edition of this otherwise valuable tome.

The book contains detailed descriptions of how assays for complement and its components are performed, and how genotyping of the polymorphic components is done (I know of no other single volume where such information is conveniently gathered together). Selective reading of the contents can provide a broad picture of the interactions of the complement proteins and their receptors, as well as their importance in pathophysiology and disease states, but at another level the book also gives the detailed information that one might expect to find in a laboratory manual.

Fred S. Rosen is the James L. Gamble Professor of Pediatrics at Harvard Medical School, and President of the Center for Blood Research, 800 Huntington Avenue, Boston, Massachusetts 02115 , USA.

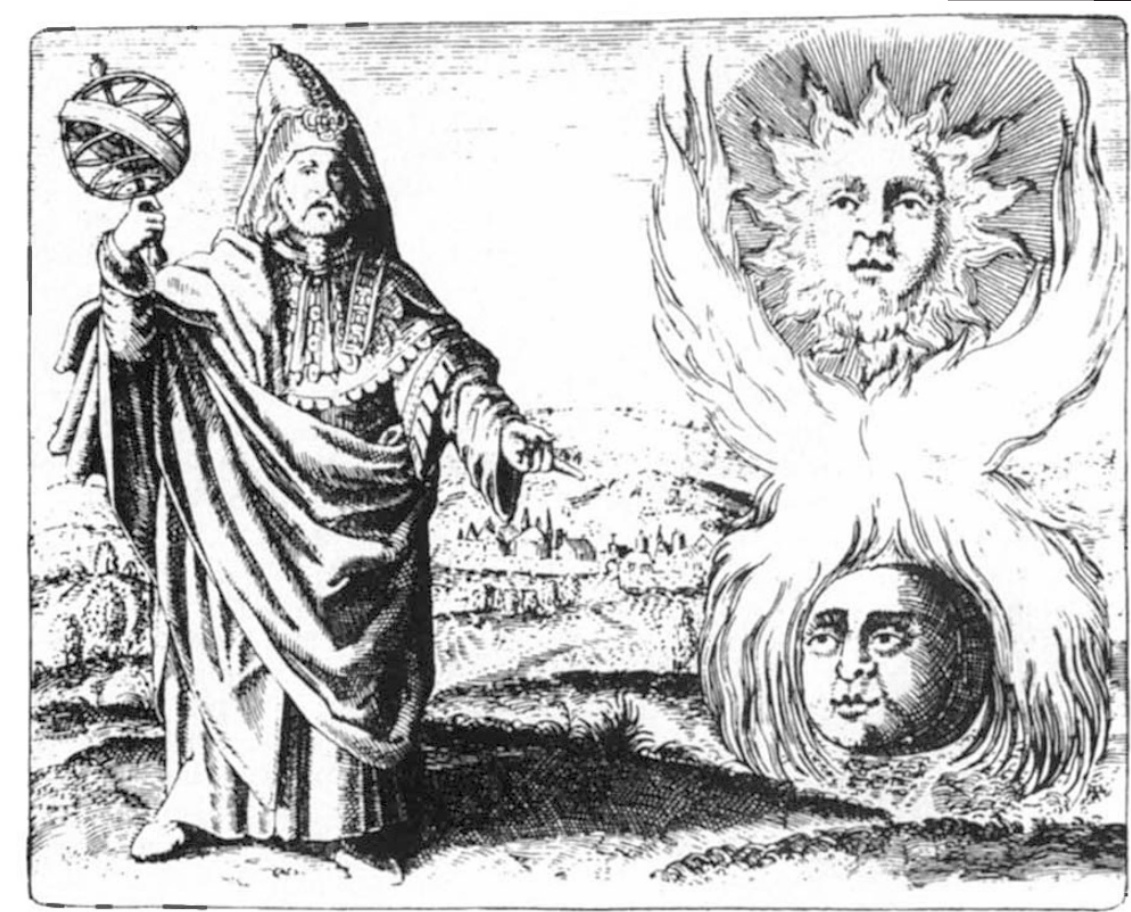

Going for gold - Hermes Trismegistus, the father of alchemy or the 'Hermetick Philosophy' here indicating the win principles of the Work, Sulphur and Mercury (the Sun and Moon). The sphere which Hermes holds is a reminder of the cosmic agent whose influence is necessary for the (rystallization of the Philosophers' Stone, the goal of alchemy, which is capable of healing all ills and transmuting all me'tals into gold. The picture, from Michael Maier's Symbola aureac mensae (1617) is reproduced in The Golden Game: Alchemical Engravings of the Seventeenth Century by Stanislas Klossowski de Rola, just published by Thames \& Hudson, price $£ 30, \$ 45$. 